\title{
A Systematic Review of Electronic Portal Usage Among Patients with Diabetes
}

\author{
Daniel J. Amante, MPH, ${ }^{1,2}$ Timothy P. Hogan, $\mathrm{PhD}_{1}^{2,3}$ Sherry L. Pagoto, $\mathrm{PhD}^{4}$ \\ and Thomas M. English, PhD $^{2}$
}

\begin{abstract}
The objectives of this review were (1) to examine characteristics associated with enrollment and utilization of portals among patients with diabetes and (2) to identify barriers and facilitators of electronic patient portal enrollment and utilization. PubMed and the Cumulative Index to Nursing and Allied Health Literature (CINAHL) were systematically searched for papers reporting original research using quantitative or qualitative methods on characteristics, barriers, and facilitators associated with portal enrollment and utilization among patients with diabetes in the United States. The search was limited to articles published between February 1, 2005 (the date of the national symposium on personal health records) and January 1, 2014. Sixteen articles were identified. Of these, nine were quantitative, three were qualitative, and four used mixed-methods. Several demographic characteristics, having better-controlled diabetes, and providers who engaged in and encouraged portal use were associated with increased portal enrollment and utilization. Barriers to portal enrollment included a lack of patient (1) capacity, (2) desire, and (3) awareness of portal/portal functions. Barriers to portal utilization included (1) patient capacity, (2) lack of provider and patient buy-in to portal benefits, and (3) negative patient experiences using portals. Facilitators of portal enrollment and utilization were providers and family members recommending and engaging in portal use. Improved usability, increased access, educating patients how to use and benefit from portals, and greater endorsement by providers and family members might increase portal enrollment and utilization. As more providers and hospitals offer portals, addressing barriers and leveraging facilitators may help patients with diabetes achieve potential benefits.
\end{abstract}

\section{Background}

T he American Diabetes Association estimates that more than 22 million Americans suffer from type 1 or type 2 diabetes, ${ }^{1}$ making diabetes one of the most prevalent diseases in the United States. Diabetes prevalence is also on the rise, having nearly doubled in the last decade. ${ }^{2}$ The rising prevalence of diabetes makes it increasingly difficult for providers to supply the continuous support required to properly manage the patient population. Crossing the Quality Chasm, a 2001 report by the Institute of Medicine, called for fundamental changes in how health care is delivered in the United States. ${ }^{3}$ A point of emphasis in this report is that care should become more "patient-centered", such that patients are put in greater charge of their own health. The report also stated that to improve the health of individuals will require more integrated care, characterized by greater coordination, continuous service over time and between visits, improved tailoring to patients' needs and preferences, and a shared responsibility between patient and providers. ${ }^{4}$ This is especially true for patients with complex, chronic diseases such as diabetes. $^{5}$

Self-management is one of the main components of the chronic care model, a framework that has been shown to improve outcome measures, reduce healthcare costs, and lower the use of healthcare services. ${ }^{6}$ Bayliss et al. ${ }^{7}$ define

\footnotetext{
${ }^{1}$ Clinical \& Population Health Research Doctoral Program, Graduate School of Biomedical Sciences, University of Massachusetts Medical School, Worcester, Massachusetts.

${ }^{2}$ Division of Health Informatics and Implementation Science, Department of Quantitative Health Sciences, University of Massachusetts Medical School, Worcester, Massachusetts.

${ }^{3}$ Center for Healthcare Organization and Implementation Research, eHealth Quality Enhancement Research Initiative (QUERI), National eHealth QUERI Coordinating Center, Bedford, Massachusetts.

${ }^{4}$ Division of Preventive and Behavioral Medicine, Department of Medicine, University of Massachusetts Medical School, Worcester, Massachusetts.
} 
self-management as "engaging in activities that promote physical and psychological health, interacting with healthcare providers and adhering to treatment recommendations, monitoring health status and making associated care decisions, and managing the impact of the illness on physical, psychological and social functioning." The electronic patient portal, a type of personal health record that allows patients to access their personal health information, manage their health condition, and communicate with their care team, is a tool that could help patients accomplish such tasks. The objectives of this article are to examine characteristics associated with enrollment in and utilization of portals among patients with diabetes and to identify barriers and facilitators of portal enrollment and utilization.

\section{Electronic Patient Portal: A Definition}

The electronic patient portal is an online personal health record that is "tethered" with a healthcare provider's electronic health record system. ${ }^{8}$ Portals enable patients to access personal health information made available to them by their providers and manage other information that they may enter into the system themselves. A portal can also accommodate patient-centered care by facilitating interaction and secure communication between patients and their clinical team and providing patients with other valuable tools to manage their health information. Functions of portals vary across healthcare systems but may include online appointment scheduling and reminders, prescription refill requests, provision of tailored health education information, journaling and tracking tools, and the ability to upload and manage other health information, such as blood glucose readings. ${ }^{9}$ In general, portals can provide patients with an efficient way to access their health information, receive additional needed support, assist in the management of their disease, and improve the overall quality of care received. ${ }^{6,10}$

Portals have been increasingly offered to patients in an effort to bridge episodic care, facilitate access to services in-between normal clinical visits, and promote selfmanagement. It was recently estimated that over 70 million Americans have access to some form of personal health record. ${ }^{11}$ The use of portals among patients with diabetes has resulted in improved clinical outcomes, such as reduced hemoglobin A1c (HbA1c) and cholesterol levels, ${ }^{9,12-14}$ patient-provider communication, disease management, patient satisfaction, and self-efficacy. ${ }^{9,15}$ Portal use with secure messaging also decreases primary care visits in general patient populations ${ }^{16}$ and urgent care utilization among Veterans. ${ }^{17}$ As part of the Health Information Technology for Economic and Clinical Health Act, over 5 billion dollars of additional Medicare and Medicaid reimbursements have been granted to providers and hospitals during Stage 1 of demonstrating meaningful use of electronic health records. In Stage 1, portal use is optional. Beginning in 2015, during Stage 2, however, portal use becomes mandatory to receive financial benefits. ${ }^{18}$

The increasing investments being made in portals stress the importance of analyzing existing literature on portal enrollment and utilization. Despite the potential benefits, enrollment and utilization of portals have been hindered by several barriers. ${ }^{19}$ To our knowledge, an in-depth look at the characteristics associated with enrollment and utilization of portals by patients with diabetes, as well as the barriers and facilitators for each, has yet to be done. Results from this search will inform interventions and implementation strategies aimed at increasing portal enrollment and usage among patients with type 1 and type 2 diabetes.

\section{Materials and Methods}

\section{Identification of articles}

The four phases of the Preferred Reporting Items for Systematic reviews and Meta-Analyses (PRISMA) statement were followed in this review. ${ }^{20}$ Searches to identify articles were performed using PubMed and the Cumulative Index to Nursing and Allied Health literature (CINAHL) databases. Search terms included the following combinations: diabetes and (1) "patient portal," (2) Internet and portal, (3) Internet and self-management, (4) "personal health record," and (5) "secure messaging" (Fig. 1). The references of identified articles and selected reviews were also examined to search for additional articles satisfying inclusion criteria. A research librarian was consulted to discuss the selection of databases and search terms to identify potential articles.

\section{Inclusion and exclusion criteria}

First, all articles had to include portals used by patients with diabetes. Second, the portals had to be clinically integrated so patients had access to personal health information, providers had access to data entered by patients, or patients could communicate with their providers through secure messaging. Third, articles had to contain original research findings on characteristics, barriers, or facilitators associated with portal enrollment and utilization using either quantitative or qualitative methods. Fourth, studies had to have at least 10 participants. Fifth, articles had to be published in peer-reviewed, English-language journals between February 2005 and January 2014. February 2005 was selected as the start point because that is when an important symposium on personal health records was held by the American Medical Informatics Association's College of Medical Informatics. ${ }^{21}$ Lastly, only articles from studies within the United States were included in this review because the U.S. healthcare system is unique and data from other countries may not be relevant.

Articles were excluded if they were a review, editorial, or commentary article, if they pooled data from patients with and without diabetes, or if the focus of the article was on the design of a portal.

\section{Data abstraction}

Electronic abstraction forms were created and used by one of the authors (D.J.A.) to abstract all data. Article characteristics collected included the number and type of participants (adults, children, providers), type of diabetes (1 or 2), methods used (quantitative, including randomized controlled trials, cross-sectional, or cohort article, or qualitative, including focus groups or open-ended questions), and key functions of the portal. A recent review on portals reported the most common portal functions include secure messaging to providers, access to notes, access to test/lab results, requesting prescription refills, appointment scheduling/reminders, and access to educational resources. ${ }^{22}$ Data were also collected if portals allowed for glucose uploads or offered weight, 


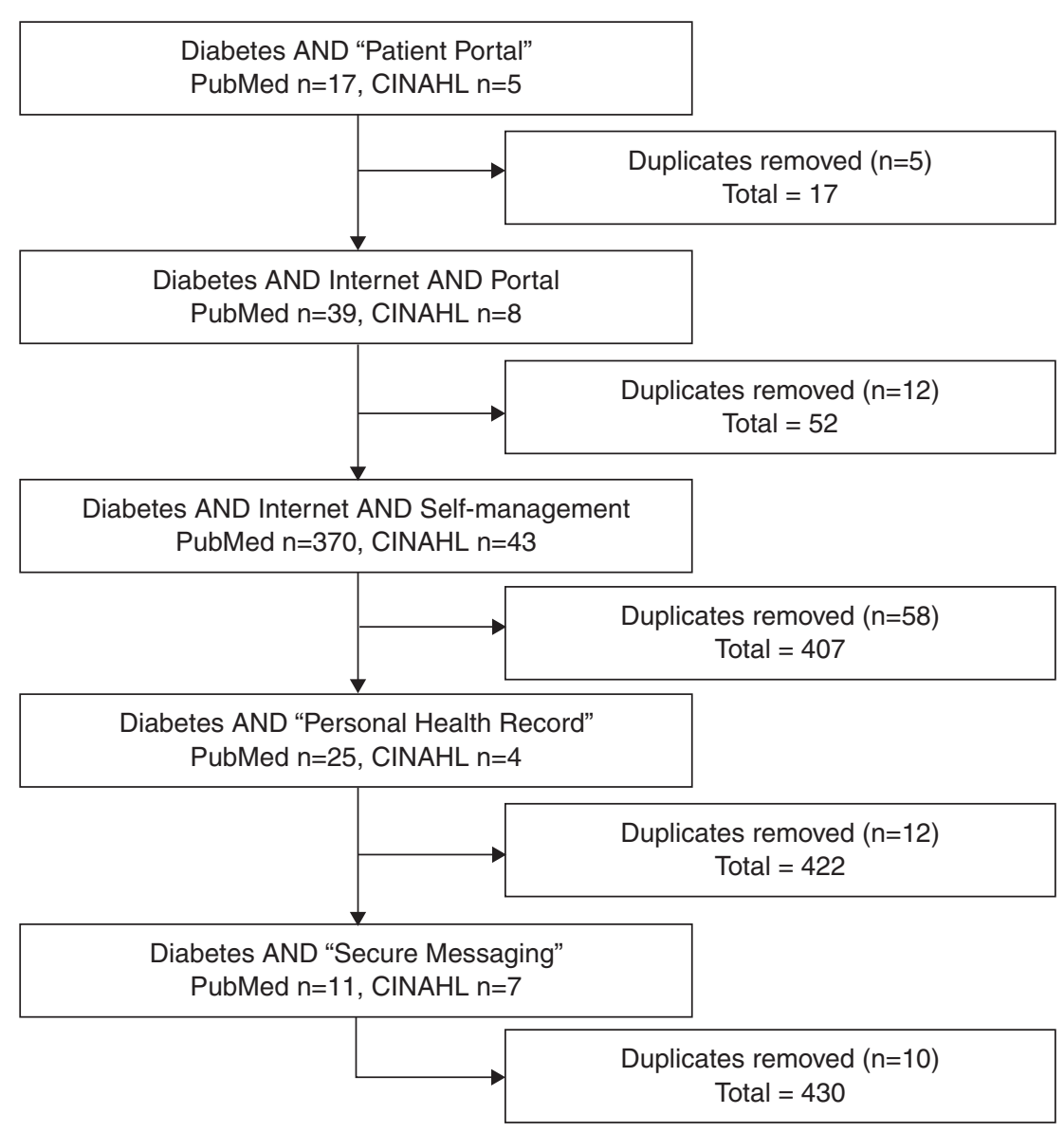

FIG. 1. Flow diagram of search terms used in PubMed and Cumulative Index to Nursing and Allied Health Literature (CINAHL).

activity, or diet logs, given the potential importance of these functions for diabetes management.

Data were abstracted on all variables that were reported statistically associated with increased portal enrollment or utilization in any of the quantitative articles. Statistical significance was defined as either $P<0.05$ for $t$ test, $\chi^{2}$ test, Fisher's exact test, Spearman's correlation coefficients, and Mann-Whitney U tests or a $95 \%$ confidence interval excluding the value of 1 for odds ratios, hazard ratios, and relative risks from regression models. Portal enrollment was defined as either expressing interest in registering for a portal, registering for a portal, requesting a password to use a portal, or using the portal at least once. Portal utilization was defined as either frequency of accessing or logging into a portal, rates of portal-facilitated secure message exchanges, number of glucose uploads, or self-reported portal utilization rates.

\section{Analytic methods}

For every variable found to be statistically associated with increased portal enrollment or utilization in any of the articles, the total number of articles that looked at the relationship between the variable and enrollment or utilization was recorded. Also recorded was whether each article found a significantly positive, negative, or no statistical association between the variable and portal enrollment or utilization. In articles that reported both crude and adjusted associations, the adjusted results were recorded. For articles that reported an association between having lower HbAlc, cholesterol, blood pressure, or diabetes-related distress and portal en- rollment or utilization, we grouped these factors together under the variable of having "better-controlled diabetes." Morbidity burden was calculated using the Johns Hopkins Adjusted Clinical Groups case mix system in one article ${ }^{23}$ and the Adjusted Clinical Groups concurrent cost weights in another article. ${ }^{24}$ Results from both were grouped together in the "high morbidity burden" variable. Data were collected on all identified barriers or facilitators to both portal enrollment and portal utilization from the qualitative articles.

\section{Assessment of article quality}

The quality of each article was evaluated using the Mixed Methods Appraisal Tool (MMAT). ${ }^{25}$ The MMAT was designed to appraise systematic literature reviews that include qualitative, quantitative, and mixed-methods articles. Quantitative articles are divided into three subdomains: randomized controlled, nonrandomized, and descriptive. Articles (qualitative, quantitative, and mixed-methods) are scored a 0-4 point scale, allowing for a standardized range of quality scores across all types of articles. In the case of mixedmethods articles, the overall quality score is the lowest score of any of the article's components.

\section{Results}

\section{Description of included articles}

The initial search resulted in 527 potential articles. After 97 duplicates were removed and 430 abstracts were screened for relevancy, 82 articles remained for full text review. Two 
additional articles were identified from bibliographies during full text review, and of these articles, 16 met all inclusion criteria. The most common reasons for excluding an article after full review were a lack of either qualitative or quantitative data on variables associated with portal enrollment or utilization $(n=30)$ or the portal in the article was not clinically integrated $(n=19)$ (Fig. 2$)$. Three sets of included articles ${ }^{26-31}$ originated from the same datasets; however, each article in all three sets examined and reported on different factors associated with portal enrollment and utilization. In one case where two articles from the same dataset both reported that non-Hispanic, non-black patients and patients with higher education were more likely to both enroll and utilize portals, ${ }^{26,27}$ results from only one of the articles were recorded. ${ }^{27}$

Characteristics of included articles are presented in Table 1. In summary, the search identified nine articles containing quantitative data only, three containing qualitative data only, and four mixed-methods articles. All 16 articles involved portals that accommodated secure messaging, whereas the portals in $13(81 \%)$ of the articles allowed patients to access test or lab results, and $11(69 \%)$ of the articles described portals that allowed patients to refill prescriptions and schedule appointments (data not shown).

Articles that reported differences in portal enrollment or utilization by education level either compared enrollment/ utilization rates among those with a college degree or some college experience with those without, $24,26,27,32$ examined total years of education attainment among those who enrolled in/utilized portals compared with those who did not, ${ }^{31,33}$ or used census data to compare high school completion rates in the areas that patients who enrolled in/utilized portals lived in compared with the areas of those who did not enroll in/utilize portals. ${ }^{34}$ Articles that reported differences in portal enrollment or utilization by age either compared enrollment or utilization rates among age groups of patients, specifically, groups over 75 years old, 70-74 years old, and 65-69 years old, ${ }^{23}$ groups less than 50 years of age, 50-64 years old, and at least 65 years old, ${ }^{24}$ those over 70 years of age with those under 70 years of age, ${ }^{27}$ or groups 30-39 years old with groups 40-49, 50-59, 60-69, and over 70 years old, ${ }^{26}$ or compared the mean age of patients who enrolled/utilized portals with the mean age of those who did not. ${ }^{31-34}$ Articles that reported differences in portal enrollment and utilization by income compared groups of household incomes less than $\$ 25,000, \$ 25,000-49,000$, and greater than $\$ 50,000,{ }^{24}$ household income less than $\$ 30,000$ with greater than $\$ 30,000,{ }^{32}$ groups of household income less than $\$ 39,999$, $\$ 40,000$ 59,999 , and greater than $\$ 60,000,{ }^{31,33}$ groups of household income greater than $\$ 65,000$ with less than $\$ 14,999$, $\$ 15,000-24,999, \$ 25,000-34,999$, and $\$ 35,000-64,999,{ }^{26}$ used neighborhood socioeconomic status to compare those who enrolled in/utilized with those who did not, ${ }^{23}$ or examined differences in mean household income among those who enrolled in or utilized portals with those who did not. ${ }^{34}$

\section{Quality of articles}

The majority of articles included scored a 3 or 4 on the MMAT scale, representing articles of high quality. Of the nine quantitative articles, eight had a score of $4,{ }^{23,26,27,34-38}$ and one had a score of $3 .{ }^{32}$ All four of the mixed-methods

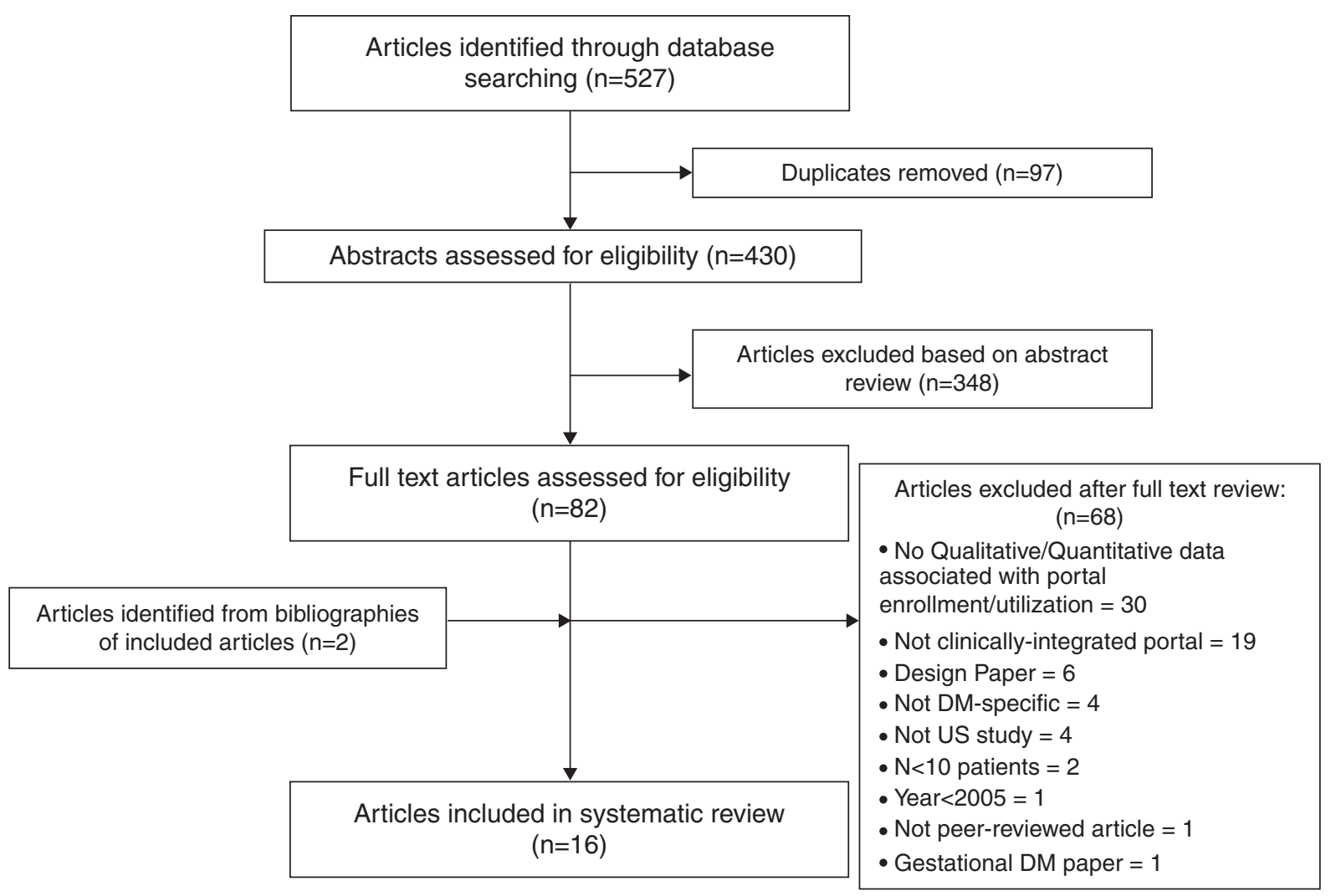

FIG. 2. Flow diagram of articles considered for inclusion in the systematic review. DM, diabetes mellitus. 
Table 1. Article Characteristics

\begin{tabular}{|c|c|c|c|c|c|c|}
\hline \multirow[b]{2}{*}{ Reference (year) } & \multirow[b]{2}{*}{ Sample, DM type } & \multirow[b]{2}{*}{ Study design } & \multicolumn{2}{|c|}{$\begin{array}{l}\text { Reported qualitative } \\
\quad \text { findings }\end{array}$} & \multicolumn{2}{|c|}{$\begin{array}{l}\text { Reported quantitative } \\
\quad \text { findings }\end{array}$} \\
\hline & & & $\begin{array}{l}\text { Barriers/ } \\
\text { facilitators } \\
\text { enrollment }\end{array}$ & $\begin{array}{c}\text { Barriers/ } \\
\text { facilitators } \\
\text { utilization }\end{array}$ & $\begin{array}{l}\text { Enrollment } \\
\text { associations }\end{array}$ & $\begin{array}{l}\text { Utilization } \\
\text { associations }\end{array}$ \\
\hline Fonda et al. ${ }^{36}$ (2009) & 104 adults, types $1+2$ & $\mathrm{RCT}$ & - & - & - & $\checkmark$ \\
\hline Harris et al. ${ }^{37}$ (2009) & 15,427 adults, types $1+2$ & Cross-sectional & - & - & - & $\checkmark$ \\
\hline Cho et al. ${ }^{32}$ (2010) & 201 adults, types $1+2$ & Cross-sectional & - & - & $\checkmark$ & - \\
\hline Sarkar et al. ${ }^{26}(2010)$ & 14,102 adults, types $1+2$ & Cohort & - & - & $\checkmark$ & $\checkmark$ \\
\hline Weppner et al. ${ }^{23}(2010)$ & 6,185 adults, types $1+2$ & Cohort & - & - & $\checkmark$ & $\checkmark$ \\
\hline Bredfeldt et al. $^{35}$ (2011) & 174 providers, types $1+2$ & Cross-sectional & - & - & $\checkmark$ & $\checkmark$ \\
\hline Sarkar et al. ${ }^{27}$ (2011) & 14,102 adults, types $1+2$ & Cohort & - & - & $\checkmark$ & $\checkmark$ \\
\hline Tenforde et al. ${ }^{34}$ (2012) & 10,746 adults, types $1+2$ & Cross-sectional & - & - & $\checkmark$ & $\checkmark$ \\
\hline Lyles et al. ${ }^{38}(2013)$ & 11,518 adults, types $1+2$ & Cohort & - & - & $\checkmark$ & $\checkmark$ \\
\hline Hess et al. ${ }^{28}$ (2007) & 39 adults, types $1+2$ & Focus groups & - & $\checkmark$ & - & - \\
\hline Zickmund et al. ${ }^{29}$ (2008) & 39 adults, types $1+2$ & Focus groups & $\checkmark$ & - & - & - \\
\hline Jethwani et al. ${ }^{39}(2012)$ & 20 adults, type 2 & $\begin{array}{l}\text { Cohort, focus } \\
\text { groups }\end{array}$ & - & $\checkmark$ & - & - \\
\hline Mayberry et al. ${ }^{30}$ (2011) & 75 adults, type 2 & $\begin{array}{l}\text { Cohort, focus } \\
\text { groups }\end{array}$ & $\checkmark$ & $\checkmark$ & - & $\checkmark$ \\
\hline Lyles et al. ${ }^{24}$ (2012) & 718 adults, types $1+2$ & $\begin{array}{l}\text { Cross-sectional, } \\
\text { open question }\end{array}$ & - & $\checkmark$ & - & $\checkmark$ \\
\hline Osborn et al. ${ }^{31}$ (2013) & 75 adults, type 2 & $\begin{array}{l}\text { Cohort, focus } \\
\text { groups }\end{array}$ & $\checkmark$ & - & $\checkmark$ & $\checkmark$ \\
\hline $\begin{array}{l}\text { Wade-Vuturo } \\
\text { et al. }(2013)^{33}\end{array}$ & 54 adults, type 2 & $\begin{array}{l}\text { Cross-sectional, } \\
\text { focus groups }\end{array}$ & $\checkmark$ & $\checkmark$ & - & $\checkmark$ \\
\hline
\end{tabular}

DM, diabetes mellitus; RCT, randomized controlled trial.

articles scored a $4 .^{24,30,31,33}$ All three of the qualitative articles received a rating of 3 , as none of them addressed how the data reported by participants in their study may have been affected by the presence of research staff. ${ }^{28,29,39}$

\section{Quantitative outcomes}

Patient factors associated with portal enrollment. Several demographic factors were associated with higher portal enrollment, including higher education, ${ }^{27,31,32,34}$ younger age, ${ }^{23,27,32,34}$ higher income, ${ }^{23,26,31,34}$ and non-Hispanic/ non-black race $27,31,34,35$ (Table 2). Additional factors associated with higher portal enrollment were having access to a computer/Internet ${ }^{32}$ and private health insurance. ${ }^{31,34}$ Several psychosocial and disease knowledge factors were associated with higher portal enrollment, such as higher self-efficacy, more diabetes and insulin-related knowledge, and higher health literacy. ${ }^{26}$ Patients reporting greater trust in the Internet as a health information source were more likely to be enrolled in portals than those reporting lesser trust. ${ }^{32}$ Patients with better-controlled diabetes (as indicated by bettercontrolled HbA1c, cholesterol, or blood pressure) were more likely to be enrolled in portals. ${ }^{27,34}$ Other health characteristics associated with higher portal enrollment included being a nonsmoker ${ }^{34}$ and having higher morbidity burden. $^{23}$

Provider factors associated with portal enrollment. Provider-level factors associated with higher portal enrollment included having the provider engaged in use of the portal ${ }^{23}$ and patients reporting better communication with and trust in their providers ${ }^{38}$ (Table 2). Providers who scored better on quality measures, as those used in the Better Health Greater Cleveland chronic disease improvement collaborative, were also more likely to have their patients enrolled in portals. ${ }^{34}$

Patient factors associated with portal utilization. Demographic factors such as higher education, ${ }^{24,27}$ younger age, ${ }^{24,26}$ higher income, ${ }^{24}$ and non-Hispanic, non-black race $^{24,27,35}$ were associated with higher portal utilization. Other articles found no significant association between portal utilization and age, ${ }^{33}$ education, ${ }^{31,33}$ race, ${ }^{31,33}$ or income. ${ }^{31,33}$ The sample sizes of two of these studies, ${ }^{31,33}$ however, were very small. Additionally, one article found that among patients who requested a password for the portal, older subjects were more likely to utilize the portal. ${ }^{27}$ One article found that having higher health literacy was associated with higher utilization, ${ }^{26}$ whereas another article found no significant association between the two. ${ }^{30}$

Findings for diabetes-related factors were mixed. Four articles found that patients utilized portals more if they had better controlled diabetes and reported less self-perceived diabetes distress and severity. ${ }^{31,33,36,37}$ Other articles found that patients with greater morbidity burden ${ }^{23}$ or high use of clinical services ${ }^{37}$ were more likely to utilize portals. One article found that using insulin was associated with higher portal utilization. $^{24}$

Provider factors associated with portal utilization. Among the articles that examined the relationship between provider engagement and patient utilization of portals, one article reported that patients of more engaged providers had higher 
Table 2. Quantitative Article Results

\begin{tabular}{|c|c|c|c|c|c|c|c|}
\hline & \multicolumn{3}{|c|}{ Association with portal enrollment } & \multicolumn{4}{|c|}{ Association with portal utilization } \\
\hline & $\begin{array}{l}\text { Significant (+) } \\
\text { association (n) }\end{array}$ & $\begin{array}{l}\text { Nonsignificant } \\
\text { association (n) }\end{array}$ & $\underset{\mathrm{n}}{\text { Total }}$ & $\begin{array}{l}\text { Significant (+) } \\
\text { association (n) }\end{array}$ & $\begin{array}{l}\text { Significant (-) } \\
\text { association (n) }\end{array}$ & $\begin{array}{l}\text { Nonsignificant } \\
\text { association (n) }\end{array}$ & $\underset{\mathrm{n}}{\text { Total }}$ \\
\hline \multicolumn{8}{|l|}{ Demographic } \\
\hline Younger age & $4^{23,27,32,34}$ & $1^{31}$ & 5 & $2^{24,26}$ & $1^{27}$ & $1^{33}$ & 4 \\
\hline Higher education & $4^{27,31,32,34}$ & - & 4 & $2^{24,27}$ & - & $2^{31,33}$ & 4 \\
\hline $\begin{array}{l}\text { Non-Hispanic, } \\
\text { non-black }\end{array}$ & $4^{27,31,34,35}$ & - & 4 & $3^{24,27,35}$ & - & $2^{31,33}$ & 5 \\
\hline Higher income & $4^{23,26,31,34}$ & $1^{32}$ & 5 & $1^{24}$ & - & $2^{31,33}$ & 3 \\
\hline Male gender & $2^{23,34}$ & $1^{31}$ & 3 & $1^{24}$ & - & $1^{33}$ & 2 \\
\hline $\begin{array}{l}\text { Computer/Internet } \\
\text { access }\end{array}$ & $1^{32}$ & - & 1 & $1^{24}$ & - & - & 1 \\
\hline Private insurance & $2^{31,34}$ & - & 2 & - & - & - & 0 \\
\hline \multicolumn{8}{|l|}{ Patient characteristics } \\
\hline Better-controlled DM & $2^{27,34}$ & - & 2 & $4^{31,33,36,37}$ & - & - & 4 \\
\hline Nonsmoker & $1^{34}$ & - & 1 & - & - & - & 0 \\
\hline High morbidity burden & $1^{23}$ & - & 1 & $1^{23}$ & - & $1^{24}$ & 2 \\
\hline $\begin{array}{l}\text { Trust in Internet as } \\
\text { health information } \\
\text { source }\end{array}$ & $1^{32}$ & - & 1 & - & - & - & 0 \\
\hline Greater health literacy & $1^{26}$ & - & 1 & $1^{26}$ & - & $1^{30}$ & 2 \\
\hline Higher use of services & - & - & 0 & $1^{37}$ & - & & 1 \\
\hline Use of insulin & - & - & 0 & $1^{24}$ & - & - & 1 \\
\hline \multicolumn{8}{|l|}{ Provider factor } \\
\hline $\begin{array}{l}\text { Provider engaged } \\
\text { in use }\end{array}$ & $1^{23}$ & - & 1 & $1^{24}$ & - & $1^{23}$ & 2 \\
\hline $\begin{array}{l}\text { Better provider quality } \\
\text { measures }\end{array}$ & $1^{34}$ & - & 1 & $2^{34,35}$ & - & - & 1 \\
\hline $\begin{array}{l}\text { Greater trust in } \\
\text { providers }\end{array}$ & $1^{38}$ & - & 1 & $1^{38}$ & - & - & 1 \\
\hline $\begin{array}{l}\text { Better communication } \\
\text { with provider }\end{array}$ & $1^{38}$ & - & 1 & - & - & - & 0 \\
\hline $\begin{array}{l}\text { Provider } \\
\quad \text { encouraged use }\end{array}$ & - & - & 0 & $1^{24}$ & - & - & 1 \\
\hline
\end{tabular}

Numbers in the table indicate the number of articles reporting association specified in the column header and are accompanied with corresponding reference(s).

DM, diabetes mellitus.

utilization of portals, ${ }^{24}$ and one reported no significant association $^{23}$ (Table 2). Additionally, having a provider encourage use ${ }^{24}$ and patients reporting greater trust in their providers $^{38}$ and better quality ratings for their care ${ }^{34,35}$ were associated with higher patient utilization.

\section{Qualitative outcomes}

Barriers and facilitators to portal enrollment. Three categories of barriers to patient enrollment in portals were identified from results of qualitative articles: (1) capacity to use portals, (2) desire to use portals, and (3) awareness of portals (Table 3 ). With regard to capacity of patients to use portals, specific deficiencies identified included insufficient computer skills, ${ }^{31}$ lack of computer or Internet access, ${ }^{31}$ and not wanting to spend time learning the portal technology. ${ }^{29} \mathrm{~A}$ lack of desire to use the portal was noted when patients reported not wanting to spend time on the computer, already being satisfied with the provider relationship, or being able to e-mail their provider directly without using a portal. ${ }^{29}$ Others reported not knowing about the existence of the portal or were unaware of portal features. ${ }^{31}$

Two articles identified a provider or family member recommendation to enroll in the portal as a facilitator of portal enrollment. ${ }^{30,33}$ Also reported as facilitators to enrollment were dissatisfaction with the current provider-patient relationship, trouble interacting with providers and staff, and difficulty obtaining medical information. ${ }^{29}$

Barriers and facilitators to portal utilization. Barriers to portal utilization can be grouped into four categories: (1) patient capacity to use a portal, (2) patient desire to use a portal, (3) lack of provider buy-in, and (4) negative patient experiences with a portal (Table 3). Patient-level barriers involving their capacity to use a portal included being too busy or having not enough time, ${ }^{39}$ lack of computer or Internet access, ${ }^{24}$ being unaware of the portal or portal features, ${ }^{28}$ and having low knowledge or technical illiteracy. ${ }^{24}$ Barriers associated with a lack of desire to use a portal included having preconceived beliefs about technology or preferring traditional communication methods, ${ }^{24,33}$ not believing in benefits, ${ }^{39}$ or having concerns about the security of the portal. ${ }^{24}$

Additional barriers involved patients' perceptions of providers' interactions with portals and included assuming that providers won't engage in portal use or that they would be interrupted by or not reimbursed for secure messages. 33,39 
Table 3. Qualitative Article Results

\begin{tabular}{|c|c|c|c|}
\hline \multicolumn{3}{|c|}{ Barriers to portal enrollment } & \multirow{2}{*}{$\begin{array}{c}\text { Facilitators } \\
\text { to portal enrollment }\end{array}$} \\
\hline Lack of capacity & Lack of desire & Lack of awareness & \\
\hline Lack of computer skills ${ }^{31}$ & $\begin{array}{l}\text { Already satisfied with } \\
\text { provider relationship }\end{array}$ & Unaware of portal ${ }^{31}$ & $\begin{array}{l}\text { Family recommended/ } \\
\text { supported }^{30}\end{array}$ \\
\hline No computer/Internet access ${ }^{31}$ & $\begin{array}{l}\text { Already e-mail provider } \\
\quad \text { directly without portal }{ }^{29}\end{array}$ & $\begin{array}{l}\text { Unaware of } \\
\text { portal features }\end{array}$ & Provider recommended ${ }^{33}$ \\
\hline $\begin{array}{l}\text { Don't want to spend } \\
\text { time learning system } 29\end{array}$ & $\begin{array}{l}\text { Don't want to spend } \\
\text { time on computer }\end{array}$ & & $\begin{array}{l}\text { Dissatisfied with } \\
\text { provider-patient } \\
\text { relationship }{ }^{9} \\
\text { Experienced difficulty } \\
\text { obtaining medical } \\
\text { information }\end{array}$ \\
\hline \multicolumn{3}{|c|}{ Barriers to portal utilization } & \\
\hline Patient-related barriers & Provider-related barriers & Usability-related barriers & to portal utilization \\
\hline Too busy/not enough time ${ }^{39}$ & $\begin{array}{l}\text { Provider instructed } \\
\text { patient not to use }\end{array}$ & $\begin{array}{l}\text { Lost/unknown user } \\
\text { names/passwords }\end{array}$ & $\begin{array}{l}\text { Family recommended/ } \\
\text { provided support }^{30}\end{array}$ \\
\hline No computer/Internet access ${ }^{24}$ & $\begin{array}{l}\text { Providers less engaged } \\
\text { in portal use }\end{array}$ & $\begin{array}{l}\text { Negative experience } \\
\text { using portal }\end{array}$ & $\begin{array}{l}\text { Provider instructed } \\
\text { patients to use }\end{array}$ \\
\hline $\begin{array}{l}\text { Low knowledge/ } \\
\text { technical literacy }{ }^{24}\end{array}$ & $\begin{array}{l}\text { Patient assumptions of } \\
\text { provider engagement, } \\
\text { interruptions, or } \\
\text { reimbursement }^{33,39}\end{array}$ & $\begin{array}{l}\text { Can't directly message } \\
\text { all providers }{ }^{28}\end{array}$ & \\
\hline $\begin{array}{l}\text { Unaware of portal/portal } \\
\text { features }\end{array}$ & & No reminders sent ${ }^{39}$ & \\
\hline $\begin{array}{l}\text { Doubts about technology } \\
\text { and reliability of message } \\
\text { exchange, security concerns, } \\
\text { or prefer traditional } \\
\text { communication }^{24,33}\end{array}$ & & $\begin{array}{l}\text { Inaccurate patient } \\
\text { information on portal }\end{array}$ & \\
\hline Don't believe in benefits ${ }^{39}$ & & $\begin{array}{l}\text { Slow response from } \\
\text { secure messages }\end{array}$ & \\
\hline
\end{tabular}

Other provider-level barriers to portal utilization stemmed from a lack of provider buy-in for the potential benefits of portal utilization and resulted in providers being less engaged in portal use ${ }^{39}$ or instructing patients not to use the portal. ${ }^{33}$

Additional barriers to portal utilization involved negative patient experiences using a portal. These included patients not being able to log onto the portal because of lost or unknown user names and passwords, ${ }^{28}$ patients having negative experience using portals, ${ }^{33,39}$ patients having difficulty entering data into the portal, ${ }^{39}$ patients not being able to directly message all of their providers ${ }^{28}$ no reminders sent to patients to keep using a portal, ${ }^{39}$ inaccurate patient information on the portal, ${ }^{28}$ and slow responses from secure messages or concerns that message exchanges are not reliably facilitated. ${ }^{28,33}$

An identified facilitator to portal utilization was having family advocates who encouraged use, taught the skills required, and acted as delegates for the patients. ${ }^{30}$ Providers recommending patients to use the portal was also identified as a facilitator to portal utilization. ${ }^{33}$

\section{Discussion}

This review identifies factors associated with increased enrollment in and utilization of electronic patient portals by patients with diabetes. It also examines the barriers and facilitators to portal enrollment and utilization. The articles reviewed here found that characteristics such as younger age, greater education, non-minority race, and higher income were associated with increased enrollment in portals among patients with diabetes. Once enrolled, patients utilize the portal less if they experience difficulty accessing or using it, or if they or their providers don't buy into the benefits of using the portal. Providers encouraging patients to sign up and use portals, and engaging in portal use themselves, increase the enrollment and use of portals by patients. Receiving encouragement and assistance from family members is another important facilitator. Educating patients, family members, and providers on how best to use portals and on the benefits of portal use can help to ensure that they know how best to use the technology and believe that it is worth their time and effort.

\section{Clinical implications}

Major barriers to portal enrollment include inadequate access and trouble using technology. To address this, opportunities to access technologies in the clinical setting and through mobile devices such as tablets and smartphones should be made available to patients. Previous articles have shown that on-site kiosks can successfully be used to demonstrate portal functionality and that many patients subsequently want to use on-site kiosks to access portals. ${ }^{40} \mathrm{On}$-site 
kiosks could be particularly helpful for patients who do not have regular access to the Internet at home but may not help bridge episodic care once patients leave the clinical setting. Making sure portal technologies are compatible with mobile technology also is likely to increase the number of people with access to portals outside of their clinic visits. A 2012 report by the Pew Internet \& American Life Atudy indicates that among smartphone owners, minorities, those with no college experience, and those with lower household income levels are all more likely to report their phone being their main source of Internet access. ${ }^{41}$ Our search found several articles that reported these groups of patients are less likely to enroll in and utilize patient portals. Making portals compatible with mobile technologies could therefore increase enrollment in and utilization of portals in such groups of patients.

Access to technology is just one of the barriers to portal usage. Making sure patients are comfortable using the technology is also important. Patients and their family members and/or caregivers may require training on how to use computers, kiosks, or mobile technology to utilize portal functions. This is especially true considering previous research has shown that those who use the Internet to seek health information are healthier than non-Internet health information seekers. ${ }^{42}$ We also found this to be true as those with better-controlled diabetes were more likely to enroll in and use portals. This is not surprising considering patients who are more engaged in the management of their health care have better health outcomes. ${ }^{43}$ Patients with poorly controlled disease and poor management skills, however, have the most to benefit from patient portals and should be encouraged and trained as needed to use this technology accordingly.

Providers have a large influence on the choices and actions of their patients. To increase enrollment and utilization of portals, interventions on both specific subpopulations of patients and the providers and clinics that provide care to those patients are needed. Patients are more likely to adopt new ways of interacting with their healthcare providers if they are encouraged to do so. ${ }^{44}$ Tang et al. ${ }^{21}$ suggested that patients who are ill have more "teachable moments" where they are receptive to educational interventions. Other studies have used waiting room time to show promotional videos or demonstrate portal functionality, resulting in increased interest and portal registrations. ${ }^{40,45}$ Leveraging teachable moments and using time spent in waiting rooms to introduce and educate patients with diabetes on portal technology create potential to improve the quality and efficiency of care. Additionally, asynchronous secure messaging, prescription refill and appointment requests, and access to medical notes through portals could serve as efficient means of providing patients with needed health information without requiring them to receive services in-person. Compensating providers for time spent engaging in secure messages with patients will also likely promote providers to encourage portal use.

\section{Research implications}

As technologies such as portals and the way patients and providers use them continue to evolve, it is critical to continue monitoring the outcomes achieved. Relevant outcomes include how technology use impacts clinical, financial, and patient-reported outcomes. It is also important to examine how technologies are being used, who is using them, and how to improve their use. Conducting qualitative research to obtain direct insight and perspectives of patients, providers, and other important stakeholders is very important in this regard. Another essential responsibility of research is to detect any unintended consequences of using new technologies to manage health. For example, concerns about personal health information security, accuracy of data, and the effects technology may have on the patient-provider relationships should all be closely monitored. It is also important to replicate quantitative findings with studies of adequate sample sizes.

\section{Strengths}

To our knowledge, this is the first systematic review looking specifically at which patients with diabetes are enrolling in and utilizing portals and what their perceived barriers and facilitators of portal enrollment and utilization are. Patients with diabetes have a unique set of health demands. Limiting this article to patients with diabetes provides more focused implications for diabetes interventions. We also limited our search to articles from the United States because of differences with healthcare systems of other countries. Also, in an effort to be comprehensive in our literature review, we evaluated data from both qualitative and quantitative articles. Lastly, we evaluated the quality of each article using a tool designed specifically for systematic reviews containing quantitative, qualitative, and mixed-methods articles.

\section{Limitations}

Patients with type 1 and type 2 diabetes significantly differ from each other with regard to demographics and disease management. Because many articles contained data from both or failed to specify the distribution of type 1 and type 2, we could not distinguish diabetes type. Portal utilization can also be a difficult concept to quantify. We grouped frequency of accessing the portal, number of secure messages sent through the portal, number of glucose uploads, and selfreported usage together to characterize portal utilization. These actions, however, may represent different levels and types of engagement in portal utilization. Furthermore, functions of portals vary depending on the healthcare system. What functions are available impacts the decision of patients to enroll and utilize a portal. Lastly, several studies had small numbers of participants, and many findings were only reported by one or two articles. Although results of the smaller studies will particularly require further replication, their inclusion in this article still adds value as a reference resource for future studies investigating characteristics associated with enrollment and utilization of portals among patients with diabetes.

\section{Conclusions}

This review shows that patients with diabetes won't enroll in portals if they lack the skills, desire, and/or knowledge of them. Even after patients have enrolled, they won't use the portals if they experience difficulty accessing and/or using the technology, or if they or their providers don't buy into the 
potential benefits. To increase portal utilization among those who could benefit most, the technology needs to be accessible, easy to use, and secure, and both patients and providers need to believe in the portal's benefits. Provider and family encouragement to utilize portals are major facilitators to portal enrollment and utilization by patients with diabetes. Patients, their family members, and providers all need to be educated how to use the technology and be informed about the potential benefits. For providers to buy into the use of portals, they need to be educated on the benefits and may require compensation for time spent interacting with patients through the portal.

\section{Author Disclosure Statement}

No competing financial interests exist.

\section{References}

1. American Diabetes Association: Economic costs of diabetes in the U.S. in 2012. Diabetes Care 2013;36:1033-1046.

2. Centers for Disease Control and Prevention: Number (in Millions) of Civilian, Noninstitutionalized Persons with Diagnosed Diabetes, United States, 1980-2011. www.cdc .gov/diabetes/statistics/prev/national/figpersons.htm (accessed January 3, 2014).

3. Berwick DM: A user's manual for the IOM's 'Quality Chasm' report. Health Aff (Millwood) 2002;21:80-90.

4. Singer SJ, Burgers J, Friedberg M, et al.: Defining and measuring integrated patient care: promoting the next frontier in health care delivery. Med Care Res Rev 2011; 68:112-127.

5. Naylor MD: Transitional care of older adults. Annu Rev Nurs Res 2002;20:127-147.

6. Bodenheimer T, Wagner EH, Grumbach K: Improving primary care for patients with chronic illness: the chronic care model, Part 2. JAMA 2002;288:1909-1914.

7. Bayliss EA, Bosworth HB, Noel PH, et al.: Supporting selfmanagement for patients with complex medical needs: recommendations of a working group. Chronic Illn 2007;3: 167-175.

8. Bates DW, Wells S: Personal health records and health care utilization. JAMA 2012;308:2034-2036.

9. Osborn CY, Mayberry LS, Mulvaney SA, et al.: Patient web portals to improve diabetes outcomes: a systematic review. Curr Diabetes Rep 2010;10:422-435.

10. Shaw RJ, Ferranti J: Patient-provider internet portalspatient outcomes and use. Comput Inform Nurs 2011;29: 714-718; quiz 719-720.

11. Kaelber DC, Jha AK, Johnston D, et al.: A research agenda for personal health records (PHRs). J Am Med Inform Assoc 2008;15:729-736.

12. Bond GE, Burr R, Wolf FM, et al.: The effects of a webbased intervention on the physical outcomes associated with diabetes among adults age 60 and older: a randomized trial. Diabetes Technol Ther 2007;9:52-59.

13. McMahon GT, Gomes HE, Hickson Hohne S, et al.: Webbased care management in patients with poorly controlled diabetes. Diabetes Care 2005;28:1624-1629.

14. Ralston JD, Hirsch IB, Hoath J, et al.: Web-based collaborative care for type 2 diabetes: a pilot randomized trial. Diabetes Care 2009;32:234-239.

15. McCarrier KP, Ralston JD, Hirsch IB, et al.: Web-based collaborative care for type 1 diabetes: a pilot randomized trial. Diabetes Technol Ther 2009;11:211-217.
16. Zhou YY, Garrido T, Chin HL, et al.: Patient access to an electronic health record with secure messaging: impact on primary care utilization. Am J Manag Care 2007;13:418 424.

17. Shimada SL, Hogan TP, Rao SR, et al.: Patient-provider secure messaging in VA: variations in adoption and association with urgent care utilization. Med Care 2013; 51(Suppl 1):S21-S28.

18. Kannry J, Beuria P, Wang E, et al.: Personal health records: meaningful use, but for whom? Mt Sinai J Med 2012;79: 593-602.

19. Goel MS, Brown TL, Williams A, et al.: Patient reported barriers to enrolling in a patient portal. J Am Med Inform Assoc 2011;18(Suppl 1):i8-i12.

20. Moher D, Liberati A, Tetzlaff J, et al.: Preferred reporting items for systematic reviews and meta-analyses: the PRISMA statement. PLoS Med 2009;6:e1000097.

21. Tang PC, Ash JS, Bates DW, et al.: Personal health records: definitions, benefits, and strategies for overcoming barriers to adoption. J Am Med Inform Assoc 2006;13:121-126.

22. Goldzweig CL, Orshansky G, Paige NM, et al.: Electronic patient portals: evidence on health outcomes, satisfaction, efficiency, and attitudes: a systematic review. Ann Intern Med 2013;159:677-687.

23. Weppner WG, Ralston JD, Koepsell TD, et al.: Use of a shared medical record with secure messaging by older patients with diabetes. Diabetes Care 2010;33:2314-2319.

24. Lyles CR, Harris LT, Jordan L, et al.: Patient race/ethnicity and shared medical record use among diabetes patients. Med Care 2012;50:434-440.

25. Proposal: A mixed methods appraisal tool for systematic mixed studies reviews. 2011. http://mixedmethodsappraisal toolpublic.pbworks.com (accessed September 22, 2013).

26. Sarkar U, Karter AJ, Liu JY, et al.: The literacy divide: health literacy and the use of an internet-based patient portal in an integrated health system-results from the Diabetes Study of Northern California (DISTANCE). $\underline{\mathrm{J}}$ Health Commun 2010;15(Suppl 2):183-196.

27. Sarkar U, Karter AJ, Liu JY, et al.: Social disparities in internet patient portal use in diabetes: evidence that the digital divide extends beyond access. $\mathrm{J}$ Am Med Inform Assoc 2011;18:318-321.

28. Hess R, Bryce CL, Paone S, et al.: Exploring challenges and potentials of personal health records in diabetes selfmanagement: implementation and initial assessment. Telemed J E Health 2007;13:509-517.

29. Zickmund SL, Hess R, Bryce CL, et al.: Interest in the use of computerized patient portals: role of the provider-patient relationship. J Gen Intern Med 2008;23(Suppl 1):20-26.

30. Mayberry LS, Kripalani S, Rothman RL, et al.: Bridging the digital divide in diabetes: family support and implications for health literacy. Diabetes Technol Ther 2011;13: 1005-1012.

31. Osborn CY, Mayberry LS, Wallston KA, et al.: Understanding patient portal use: implications for medication management. J Med Internet Res 2013;15:e133.

32. Cho AH, Arar NH, Edelman DE, et al.: Do diabetic veterans use the Internet? Self-reported usage, skills, and interest in using My HealtheVet Web portal. Telemed J E Health 2010;16:595-602.

33. Wade-Vuturo AE, Mayberry LS, Osborn CY: Secure messaging and diabetes management: experiences and perspectives of patient portal users. J Am Med Inform Assoc 2013;20:519-525. 
34. Tenforde M, Nowacki A, Jain A, et al.: The association between personal health record use and diabetes quality measures. J Gen Intern Med 2012;27:420-424.

35. Bredfeldt $\overline{\mathrm{CE}}$, Compton-Phillips AL, Snyder MH: Effects of between visit physician-patient communication on Diabetes Recognition Program scores. Int J Qual Health Care 2011;23:664-673.

36. Fonda SJ, McMahon GT, Gomes HE, et al.: Changes in diabetes distress related to participation in an internet-based diabetes care management program and glycemic control. J Diabetes Sci Technol 2009;3:117-124.

37. Harris LT, Haneuse SJ, Martin DP, et al.: Diabetes quality of care and outpatient utilization associated with electronic patient-provider messaging: a cross-sectional analysis. Diabetes Care 2009;32:1182-1187.

38. Lyles CR, Sarkar U, Ralston JD, et al.: Patient-provider communication and trust in relation to use of an online patient portal among diabetes patients: the Diabetes and Aging Study. J Am Med Inform Assoc 2013;20:1128-1131.

39. Jethwani K, Ling E, Mohammed M, et al.: Diabetes connect: an evaluation of patient adoption and engagement in a web-based remote glucose monitoring program. J Diabetes Sci Technol 2012;6:1328-1336.

40. Ahlers-Schmidt CR, Nguyen M: Parent intention to use a patient portal as related to their children following a facilitated demonstration. Telemed J E Health 2013;19: 979-981.
41. Brown LL, Lustria ML, Rankins J: A review of webassisted interventions for diabetes management: maximizing the potential for improving health outcomes. J Diabetes Sci Technol 2007;1:892-902.

42. Cotten SR, Gupta SS: Characteristics of online and offline health information seekers and factors that discriminate between them. Soc Sci Med 2004;59:1795-1806.

43. Hibbard JH, Greene J: What the evidence shows about patient activation: better health outcomes and care experiences; fewer data on costs. Health Aff (Millwood) 2013;32: 207-214.

44. Kinney AY, Richards C, Vernon SW, et al.: The effect of physician recommendation on enrollment in the Breast Cancer Chemoprevention Trial. Prev Med 1998;27:713-719.

45. North F, Hanna BK, Crane SJ, et al.: Patient portal doldrums: does an exam room promotional video during an office visit increase patient portal registrations and portal use? J Am Med Inform Assoc 2011;18(Suppl 1):i24-i27.

Address correspondence to: Daniel J. Amante, MPH

Quantitative Health Sciences University of Massachusetts Medical School 368 Plantation Street Worcester, MA 01605

E-mail: daniel.amante@umassmed.edu 